\title{
Clinical and electrophysiological correlates of TTRala71 amyloid neuropathy
}

\author{
Wilson Marques Jr${ }^{1}$, Vinicius S. Borghetti ${ }^{1}$, Vanessa D. Marques ${ }^{1}$, \\ Luciano Neder², Facundo B. Ruiz Jr³, Amílton A. Barreira'
}

The familial amyloidotic polyneuropathies (FAP) are autosomal dominant, length-dependent, axonal neuropathies first described in Portugal in 1958 ${ }^{1}$. They were later shown to be heterogeneous, resulting from tissue deposition of abnormal variants of physiological proteins, including transthyretin (TTR), apolipoprotein-A1 and gelsolin ${ }^{1,2}$. Mutations in the TTR gene are their most common cause, and the replacement of a valine for methionine at aminoacid position 30 of the TTR protein (TTR Val30Met) is the most frequent mutation, although there are at least 70 different mutations (Human Gene Mutation Database - HGMD) identified. TTR mutations are prevalent in Portugal, Japan, Ireland, Majorca and Sweden. In contrast to Japan, where several mutations coexist, in Portugal the TTRmet30 substitution was the single known pathogenic mutation until the year 2000, when the Val28Met mutation was found ${ }^{3}$. In Portuguese descents, the same mutational prevalence for the TTRmet30 seems to be present. Diagnosis is usually based on clinical manifestations, family history, and identification of the mutation.

The Brazilian patient we describe had no family history of an inherited disease, his neuropathy has unusual clinical and electrophysiological characteristics, and he tested negative for the TTRmet30 in a country of Portuguese descent, resulting in late diagnosis and inappropriate therapy for a long period of time.

\section{CASE}

A 37-year-old white male patient, of unknown descent, was referred to our hospital as a case of corticosteroid unresponsive chronic inflammatory demyelinating polyradiculoneuropathy (CIDP). Two years previously he presented burning and "pins and needles" sensations in his feet and hands, that progressed to a state of continuous pain and loss of pain sensation in his feet, legs and hands. Later, the proximal thighs, and the forearms became affected. Fourteen months after onset, he noticed difficulty in running, and some months later walking became abnormal, following trips and falls. More recently, a progressive difficulty in rising and climbing stairs appeared. Bladder and bowel functions were normal, although vomiting, attributed to a gall bladder disease, was frequent. He lost $30 \mathrm{~kg}$ since the onset of the disease and recovered almost $10 \mathrm{~kg}$ after a gall bladder surgery, which significantly improved his gastrointestinal manifestations. There was no family history of a similar condition. A nerve conduction study (NCS) performed elsewhere (data not available) revealed a demyelinating neuropathy, and he was treated with $60 \mathrm{mg}$ of prednisone for 60 days, without any improvement. On examination, he walked with dropped feet, his sense of position was normal but vibration was absent in the toes, moderately decreased in the ankles, and mildly decreased in up to the knees and fingers. Pain and tactile sensations were absent to the middle third of the legs, and mildly decreased to the base of the thighs, to the proximal third of forearms and around the navel. There was hy-

\section{CORRELAÇÃO CLÍNICA E ELETROFISIOLÓGICA COM A NEUROPATIA AMILÓIDE TTRala71}

Received 2 February 2009

Received in final form 20 June 2009 Accepted 8 September 2009

'Departments of Neurosciences and Behavioral Sciences and ${ }^{2} P a t h o l o g y$, School of Medicine of Ribeirão Preto, University of São Paulo, Ribeirão Preto SP, Brazil; Department of Neurology ${ }^{3}$, Federal School of Medicine of Uberlândia, Uberlândia MG, Brazil . 
Table. Motor and sensory nerve conduction studies.

\begin{tabular}{|c|c|c|c|c|c|c|c|c|c|c|c|}
\hline \multirow[b]{2}{*}{ Nerve } & \multicolumn{9}{|c|}{ CMAP } & \multicolumn{2}{|c|}{ SNAP } \\
\hline & $\mathrm{DL}$ & $\mathrm{A} 1$ & $\mathrm{~A} 2$ & A3 & A4 & CV12 & CV23 & CV34 & $\mathrm{Fw}$ & $A$ & VC \\
\hline R-median & 4.2 & 2.3 & 2.1 & 2.0 & - & 49.0 & 41.4 & - & $\mathrm{Nr}$ & 0.8 & 48.2 \\
\hline L-median & 4.6 & 2.5 & 2.5 & 2.1 & - & 49.0 & 35.1 & - & $\mathrm{Nr}$ & 0.8 & 49.3 \\
\hline R-ulnar & 2.7 & 2.2 & 2.1 & 2.0 & 1.8 & 49.0 & 40.5 & 45.0 & 37.3 & 0.4 & 49.2 \\
\hline L-ulnar & 2.7 & 2.4 & 1.3 & 1.1 & 1.1 & 49.2 & 45.0 & 40.5 & 32.2 & 0.9 & 52.3 \\
\hline R-peroneal & $\mathrm{Nr}$ & $\mathrm{Nr}$ & $\mathrm{Nr}$ & $\mathrm{Nr}$ & $\mathrm{Nr}$ & $\mathrm{Nr}$ & $\mathrm{Nr}$ & $\mathrm{Nr}$ & $\mathrm{Nr}$ & $\mathrm{Nr}$ & $\mathrm{Nr}$ \\
\hline L-peroneal & $\mathrm{Nr}$ & $\mathrm{Nr}$ & $\mathrm{Nr}$ & $\mathrm{Nr}$ & $\mathrm{Nr}$ & $\mathrm{Nr}$ & $\mathrm{Nr}$ & $\mathrm{Nr}$ & $\mathrm{Nr}$ & $\mathrm{Nr}$ & $\mathrm{Nr}$ \\
\hline R-tibial & $\mathrm{Nr}$ & $\mathrm{Nr}$ & $\mathrm{Nr}$ & $\mathrm{Nr}$ & $\mathrm{Nr}$ & $\mathrm{Nr}$ & $\mathrm{Nr}$ & $\mathrm{Nr}$ & $\mathrm{Nr}$ & $\mathrm{Nr}$ & $\mathrm{Nr}$ \\
\hline L-tibial & $\mathrm{Nr}$ & $\mathrm{Nr}$ & $\mathrm{Nr}$ & $\mathrm{Nr}$ & $\mathrm{Nr}$ & $\mathrm{Nr}$ & $\mathrm{Nr}$ & $\mathrm{Nr}$ & $\mathrm{Nr}$ & $\mathrm{Nr}$ & $\mathrm{Nr}$ \\
\hline
\end{tabular}

A: amplitude; CMAP: compound muscule action potential; CV: conduction velocity; DL: distal latency; SAP: sensory action potential; Fw: F-waves; Nr: no response

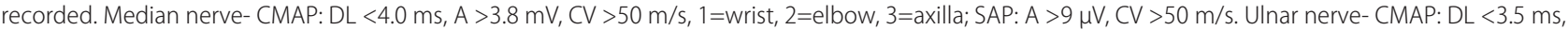
$\mathrm{A}>3.8 \mathrm{mV}, \mathrm{CV}>50 \mathrm{~m} / \mathrm{s}, 1=$ wrist, $2=\downarrow$ elbow, $3=\uparrow$ elbow, $4=$ axilla; $\mathrm{SAP}: \mathrm{A}>9 \mu \mathrm{V}, \mathrm{CV}>50 \mathrm{~m} / \mathrm{s}$. Peroneal nerve- CMAP: DL <5.0 ms, A $>2.8 \mathrm{mV}, \mathrm{CV}>40 \mathrm{~m} / \mathrm{s}$, $1=$ anklet, $2=\downarrow$ fibula neck, $3=\uparrow$ fibula neck, SAP: $A>9 \mu \mathrm{V}, \mathrm{CV}>50 \mathrm{~m} / \mathrm{s}$.

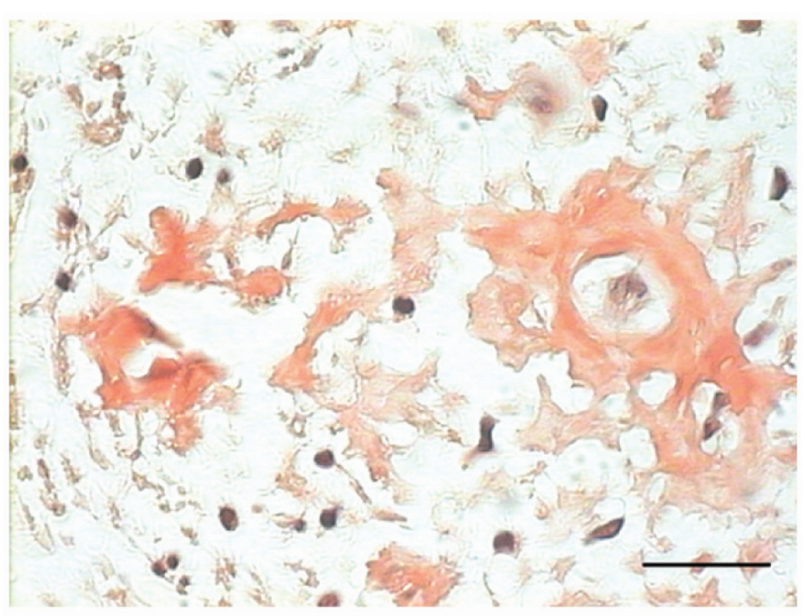

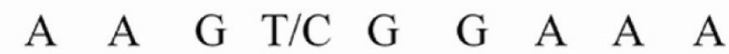

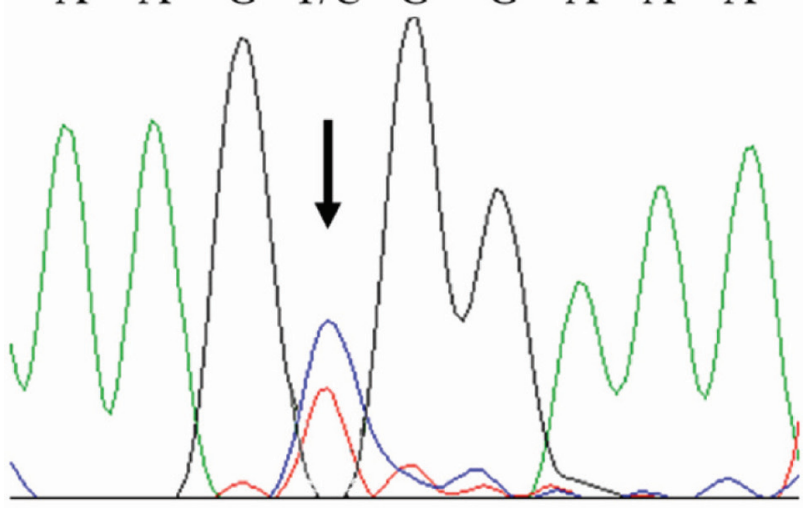

Figure. Sural nerve biopsy showing the amyloid infiltrate (above) and the electropherogram displaying the TTRAla71 mutation (bellow).

potrophy of foot and leg muscles, and a very mild loss of bulk of the intrinsic hand muscles. Strength, in the upper limbs, presented according to the modified Medical Research County scale (MRC), was normal proximally $(5 / 5)$ and very mildly decreased distally (4/5); in the low- er limbs, hip flexion and extension (4-/5), and foot flexion and extension were severely impaired (3/5). Tendon jerks were normal in the upper limbs and absent in the lower limbs. Apart a significant weight loss, the remaining clinical and neurological examination was unrelevant.

His laboratory investigation was normal, including CSF analysis. Our EMG (Table) was also suggestive of an asymmetrical demyelinating sensorimotor neuropathy, and the sural nerve biopsy revealed a severe chronic axonal neuropathy with amyloid infiltrate. No evidence of demyelination or inflammatory infiltrate was found. After informed consent, testing for the TTRmet30 mutation was negative, but due to the presence of amyloid deposits in the nerve biopsy (Figure), exons 2, 3 and 4 were sequenced, revealing the TTRala71 substitution (Figure). Immunosuppression and immunomodulatory treatments were contra-indicated and the patient was enrolled in a liver transplant program.

\section{DISCUSSION}

Although having a worldwide distribution ${ }^{1}$ and many identified mutations ( $>70)$, TTR amyloidosis is rare, has variable clinical expression, the familiar history may be unclear $^{1}$, and atypical presentations may occur. All these characteristcs may hamper an appropriated and fast diagnosis.

Although having a length-dependent, sensory painful neuropathy pattern in the initial period of the disease, the presence of an important proximal weakness in the lower limbs in the absence of a significant distal weakness in the upper limbs, and the non-uniform demyelinating pattern observed on NCS suggested this patient had a non length-dependent demyelinating neuropathy, compatible to $\mathrm{CIDP}^{4}$, that may occasionally be heralded by pain ${ }^{5}$. CSF is highly abnormal in patients with CIDP when several punctures are carried out, but one normal examination does not rule out this disease 
As there was no improvement with steroid treatment, a sural nerve biopsy was carried out, revealing an amyloid infiltrate. Subsequently, the TTR gene was screened, and the TTRala71 substitution identified.

This mutation has been previously reported just three times, none in Portuguese descents. Almeida ${ }^{6}$ described a Spanish family whose manifestations began in the third decade of life as a sensorimotor polyneuropathy accompanied by constipation and weight loss. Benson et al. ${ }^{7}$ reported a French family with a similar phenotype plus mild autonomic features and vitreous opacity. Haagsma et al. ${ }^{8}$ described a Dutch family whose disease began later, in the fifth decade of life, with a phenotype similar to the French family. This patient was submitted to liver transplantation, but died 14 months after, with no significant improvement.

Although FAP is defined as an axonal length-dependent neuropathy; asymmetrical demyelinating patterns on NCS have already been reported with other mutations ${ }^{9}$. As no detailed NCS was provided in the previous papers about the TTRala71 mutation, we can not associate the electrophysiological pattern found in our patient with this specific mutation.

In opposition to the three previous reports ${ }^{6-8}$ our patient presented as a sporadic case suggesting either new mutation or low penetrance, mechanisms already known to occur with the TTR gene. Unfortunately, we were not able to test the entire family in order to clarify this point. Recently, Plantée-Bordeneuve et al. ${ }^{10}$ demonstrated that sporadic cases are prone to late diagnosis and its deleterious consequences, like inappropriate treatments

Our data emphasize the importance of performing nerve biopsy in atypical or unresponsive CIDP cases, and of sequencing the TTR gene if an amyloid infiltrate is found or if there are significant small nerve fiber manifestations, even in the absence of a positive family history ${ }^{10}$.

\section{REFERENCES}

1. Saraiva MJM. Hereditary transthyretin amyloidosis: molecular basis and therapeutical strategies. Exp Rev Mol Med 2002;4:1-11.

2. Hund E, Linke RP, Willig F, Grau A. Transthyretin-associated neuropathic amyloidosis. Neurology 2001;56:431-435.

3. De Carvalho M, Moreira P, Evangelista T, et al. New transthyretin mutation V28M in a Portuguese kindred with amyloid polyneuropathy. Muscle Nerve 2000;23:1016-1021

4. Barreira AA, Marques W Jr. Truncal sensory loss in acquired demyelinating neuropathies. Muscle Nerve 1997;20:611-613.

5. Boukhris S, Magy L, Khalil M, Sindou P, Vallat J-M. Pain as a presenting symptom of chronic inflammatory demyelinating polyradiculoneuropathy (CIDP). J Neurol Sci 2007;254:33-38.

6. Almeida MR, Lopez-Andreu F, Munar-Qués M, Costa PP, Saraiva MJ. Transthyretin ALA 71: a new transthyretin variant in a spanish family with familial amyloidotic polyneuropathy. Human Mutation 1993;2:420-421.

7. Benson II MD, Turpin JC, Lucotte G, Zeldenrust S, LeChevalier B, Benson MD. A Transthyretin variant (alanine 71) associated with familial amyloidotic polyneuropathy in a French family. J Med Genet 1993;30:120-122.

8. Haagsma EB, Scheffer H, Altland K, De Jager AEJ, Hazemberg BPC. Transthyretin Val71Ala mutation in a Dutch family with familial amyloidotic polyneuropathy. Amyloid. Int J Exp Clin Invest 2000;7:218-221.

9. Briemberg HR, Amato AA. Transthyretin amyloidosis presenting with multifocal demyelinating mononeuropathies. Muscle Nerve 2004;29:318-322.

10. Plantée-bordeneuve V, Ferreira A, Lalu T, et al. Diagnostic pitfalls in sporadic transthyretin familial amyloid polyneuropathy (TTR-FAP). Neurology 2007;69: 694-698. 